UDC 332.142 .4

LBC 65.01

\title{
THE TOURISM POTENTIAL OF THE REPUBLIC OF KALMYKIA AND ITS ROLE IN THE REGIONAL ECONOMY
}

\author{
Elena S. Avaldykova \\ Kalmyk State University named after B.B. Gorodovikov, Elista, Republic of Kalmykia, Russian Federation \\ Tamara T. Tsatkhlanova \\ Kalmyk State University named after B.B. Gorodovikov, Elista, Republic of Kalmykia, Russian Federation
}

\begin{abstract}
Tourism is a sector of the economy, which is constantly evolving and plays a significant role in the formation of GDP. The term 'destination' can be interpreted as the territory equipped with facilities and advanced system of services to meet all basic needs of tourists.

Richly developed tourist destination within the region is one of the key elements of the system, which is designed to encourage tourists' interest in a particular area and to motivate their visit there, thus enhancing the tourism system as a whole.

Analyzing the tourism potential of the territory of the Republic of Kalmykia, it is difficult to overestimate the unique set of historical, cultural and natural heritage of the Kalmyk people, as well as favorable geographical location of the territory and the uniqueness of the Buddhist people in the European part of Russia. Thus, Kalmykia has a huge potential to become a tourist destination and develop such types of tourism, as gastronomical, cultural, religious, environmental, family, and cognitive.

It should be noted that currently the Republic is actively developing the event tourism, which is recreation dedicated to a certain event or participation in any entertainment. According to the results of the competition ranking of International tourism forum Rest ('Otdykh'), the Republic was ranked $15^{\text {th }}$ in the first National ranking of the development of tourism in Russia in 2016.

The development of tourist destinations in the Republic is prospective from the viewpoint of stimulating economic development in the region through participation in Federal target programs 'Development of domestic and inbound tourism in the Russian Federation (2011-2018)' and 'Development of culture and tourism of the Russian Federation (2013-2020)', aimed at increasing the competitiveness of domestic tourism market, which would meet the needs of Russian and foreign citizens in high-quality tourist services.

The creation of tourist destinations in the territory of the Republic of Kalmykia can be a tool in the fight against the main socio-economic problems of the region and give background to stimulate the development of small and medium enterprises (SMEs), the creation of jobs, the reduction of migration, regional infrastructure development, etc.

Key words: tourism, regional economy, tourism potential, region, culture, analysis.
\end{abstract}

\section{ТУРИСТИЧЕСКИЙ ПОТЕНЦИАЛ РЕСПУБЛИКИ КАЛМЫКИЯ И ЕГО РОЛЬ В РЕГИОНАЛЬНОЙ ЭКОНОМИКЕ}

\section{Елена Саранговна Авалдыкова}

Калмыцкий государственный университет им. Б.Б. Городовикова, г. Элиста, Республика Калмыкия, Российская Федерация

\section{Тамара Тавиновна Цатхланова}

Калмыцкий государственный университет им. Б.Б. Городовикова, г. Элиста, Республика Калмыкия, Российская Федерация 
Аннотация. Богато развитая туристическая дестинация внутри региона является одним из ключевых элементов системы, которая призвана побуждать интерес к определенной территории и мотивировать визит потоков туристов, таким образом, активизируя туристическую систему в целом.

Анализируя туристический потенциал территории Республики Калмыкия, трудно переоценить уникальный набор историко-культурного и природного наследия калмыцкого народа, а также комфортного географического местоположения территории и уникальности буддийского народа в европейской части России. Из этого следует, что Калмыкия имеет огромный недооцененный потенциал для создания туристической дестинации и развития таких направлений туризма, как гастрономический, культурный, религиозный, экологический, семейный, культурно-познавательный.

Сегодня в Калмыкии активно развивается событийный туризм, который представляет собой организацию отдыха, приуроченную к какому-либо событию или участию в каких-либо зрелищных мероприятиях. По итогам конкурса-рейтинга Международного туристического форума «Отдых», республика вошла в топ- 15 первого Национального рейтинга развития событийного туризма России 2016 года.

Развитие туристической дестинации республики имеет определенные перспективы для стимулирования развития экономики региона посредством участия в федеральных целевых программах «Развитие внутреннего и въездного туризма в Российской Федерации (2011-2018 гг.)», а также «Развитие культуры и туризма Российской Федерации (2013-2020 гг.)», целью которых определено повышение конкурентоспособности отечественного туристского рынка, удовлетворяющего потребности российских и иностранных граждан в качественных туристских услугах, что соответствует цели Концепции.

Именно создание туристических дестинаций на территории Республики Калмыкия может послужить одним из инструментов борьбы с основными социально-экономическими проблемами региона и дать предпосылки к стимулированию развития таких важных факторов, как малое и среднее предпринимательство (МСП), формирование рабочих мест, снижение уровня миграции населения, развитие инфраструктуры региона и т. д.

Ключевые слова: туризм, региональная экономика, туристический потенциал, регион, культура, анализ.

Туристический потенциал - это совокупность ряда отличительных качеств территории, выраженная в исторической, культурной, природной, а также климатической специфике с учетом экономического развития и возможных предпосылок для создания развивающейся туристической дестинации.

Понятие «туристическая дестинация» вошло в лексикон отечественной туристической индустрии с недавних пор и является заимствованным термином (с англ. destination). Термин «дестинация» можно трактовать как территорию, оснащенную соответствующей инфраструктурой, удобствами и развитой системой услуг для удовлетворения всех необходимых нужд туристов. Богато развитая туристическая дестинация внутри региона является одним из ключевых элементов системы, которая призвана побуждать интерес к определенной территории и мотивировать визит потоков туристов, таким образом, активизируя туристическую систему в целом [1].

Туризм - это отрасль экономики, которая постоянно развивается, а также играет значительную роль в формировании ВВП и основных социально-экономических показателей.
Развитая система туристической дестинации, с точки зрения экономики региона, призвана решить следующие задачи:

- выявление туристического потенциала территории;

- создание рабочих мест;

- реализация развития инфраструктуры (строительство дорог, обновление памятников культуры, возведение новых современных зданий);

- спад уровня миграции трудоспособного населения за пределы территории;

- повышение уровня знаний национальной культуры;

- развитие МСП в регионе и т. д.

Для оценки туристического потенциала территории Республики Калмыкия проведем SWOT-анализ имеющихся преимуществ и недостатков (см. табл. 1).

Территория Республики Калмыкия сочетает в себе уникальный набор исторического, культурного, географического и природного наследия. Важным фактором является комфортное географическое расположение и особенности буддийской культуры в европейской части России. Таким образом, Республика Калмыкия имеет огромный потенциал для 
создания активной туристской отрасли и таких направлений как гастрономический, культурный, религиозный, экологический, семейный, культурно-познавательный туризм.

Наиболее острой проблемой в области развития туристической отрасли стоит вопрос плохо развитой системы инфраструктуры республики, которая выражена в отсутствии туристических, культурно-познавательных объектов, некачественных дорог, а также трудности с объектами водоснабжения и жизнеобеспечения. В виду отсутствия достаточного объема средств республиканского бюджета, данные вопросы требуют привлечения дополнительных ресурсов в виде субсидий федерального бюджета и инвестиционных вложений.

Особое место занимает проблема развития рынка инвестиций в республике, который является необходимой базой формирования материальной составляющей отрасли:

- трудности в процессе получения доступных банковских и государственных кредитов;
- слабо развитая система кредитной кооперации;

- отсутствие возможности привлечения средств российского и зарубежных рынков инвестиций.

Все это существенно снижает возможности местных предпринимателей, особенно в области малого бизнеса.

Раскрыв туристический потенциал региона, республика получит возможность развития бизнеса в данном направлении, который является немаловажным фактором в процессе привлечения новых потоков денежной массы и инвестиций в экономику. Именно развитие туризма и созданиетуристских дестинаций может послужить одним из инструментов борьбы с основными социально-экономическими проблемами региона и дать предпосылки к повышению конкурентоспособности региональной экономики.

Для анализа и оценки структуры учреждений истории и культуры проанализируем таблицу 2.

Таблица 1

\section{SWOT-анализ туристического комплекса Республики Калмыкия}

\begin{tabular}{|c|c|}
\hline Сильные сто & Слабые стороны \\
\hline $\begin{array}{l}\text { - чистая экология; } \\
\text { - достаточно благоприятный климат для осуществления } \\
\text { прогулок и выездов; } \\
\text { - огромное количество культурных и исторических ресурсов; } \\
\text { - доступные цены туристических продуктов; } \\
\text { - большой потенциал в отношении внедрения новых инно- } \\
\text { ваций в сфере туризма; } \\
\text { - развитие этнокультурного и экологического туризма }\end{array}$ & $\begin{array}{l}\text { - отсутствие стратегического } \\
\text { планирования; } \\
\text { - аутсайдерское п положение на } \\
\text { туррынке; } \\
\text { - скудная материальная база; } \\
\text { - неудовлетворительный уровень } \\
\text { менеджмента }\end{array}$ \\
\hline Возможности & \\
\hline $\begin{array}{l}\text { - дифференцированность туристической продукции; } \\
\text { - расширение ассортимента продуктов (туров, гостиничных } \\
\text { услуг) для удовлетворения широкого круга потребителей; } \\
\text { - качество и безопасность; } \\
\text { - возможность создания уникальной экономической зоны } \\
\text { рекреационного типа }\end{array}$ & $\begin{array}{l}\text { - несвоевременное финансиро- } \\
\text { вание со стороны федерального } \\
\text { бюджета; } \\
\text { - «захват» рынка туристических } \\
\text { услуг крупными фирмами; } \\
\text { - ухудшение состояния экологии }\end{array}$ \\
\hline
\end{tabular}

Примечание. Составлено автором по данным: [3].

Структура учреждений культуры Республики Калмыкия

\begin{tabular}{|l|r|r|r|r|r|r|}
\hline \multicolumn{1}{|c|}{ Показатели } & 2005 & 2010 & 2012 & 2013 & 2014 & 2015 \\
\hline Профессиональные театры в том числе: & 4 & 4 & 3 & 2 & 2 & 2 \\
\hline драмы, комедии, музыкальные & 3 & 3 & 2 & 2 & 2 & 2 \\
\hline детские, юного зрителя & 1 & 1 & 1 & - & - & - \\
\hline Музеи & 5 & 5 & 1 & 1 & 1 & 1 \\
\hline Библиотеки & 178 & 172 & 156 & 149 & 149 & 148 \\
\hline Учреждения культурно-досугового типа & 203 & 175 & 155 & 150 & 150 & 149 \\
\hline
\end{tabular}

Примечание. Составлено автором по данным: [4]. 
Анализ статистических данных количества учреждений культуры свидетельствует о снижении их количества в период с 2005 года. Данную ситуацию можно объяснить недостатком средств содержания и ремонта объектов культуры, сокращением числа населения, а, соответственно, спроса на услуги и развлечения в сфере культуры и досуга. Значительным фактом является свободный доступ ко всем источникам информации научного и познавательного характера посредством распространения сети Интернет.

Говоря о культурном, историческом и религиозном наследии, необходимо отметить, что территория республики богата наличием ряда уникальных объектов. Столица республики город Элиста с ее уникальными достопримечательностями: самый большой в Европе буддийский Хурул «Золотая Обитель Будды Шакъямуни», Хурул «Сякусн Сум», город шахмат «Сити-Чесс», музей им. Н.Н. Пальмова, а также природные парки и заповедники со своеобразным растительным и животным миром. Великий шелковый путь и Хазарский каганат, в древние времена проходящие на территории сегодняшней республики, которые оставили свой неизгладимый след в виде памятника архитектуры, Сарай-Бату - вторая столица Золотой Орды, до сих пор представляет интерес для археологов и историков со всего мира. Таким образом, исторически выгодное географическое положение и относительно благоприятный климат дает преимущества в привлечении туристов, которые стремятся окунуться в атмосферу умиротворения, спокойствия и единения с древней историей и культурой буддийского народа.

Актуальным видом туризма, который активно развивается на сегодняшний день в Калмыкии, является этнокультурный и событийный виды туризма. Событийный туризморганизация отдыха, приуроченная к какомулибо событию или участие в каких-либо зрелищных мероприятиях. Стоит отметить, что по итогам конкурса-рейтинга в рамках Международного туристического форума «Отдых», Республика Калмыкия вошла в бронзовую лигу первого Национального рейтинга развития событийного туризма России 2016 года. Бронзовая лига представляет собой «Территории перспективного развития», в число ко- торых входят регионы, обладающие потенциалом развития событийного туризма, с целью расширения событийного календаря и увеличения туристического потока.

Для развития событийного туризма Министерством культуры и туризма республики проводится активная работа по увеличению количества событийных мероприятий, повышению уровня проведения культурномассовых мероприятий, активизации работы по обновлению репертуара учреждений культуры [3].

Примером ярких популярных событий среди мероприятий является фестиваль тюльпанов и лотосов, праздник «Джангариада», фестиваль современной музыки монголоязычных народов «Пентатоника», национальные и религиозные праздники и многие другие. Подобные мероприятия способствуют продвижению национальных, культурных особенностей и традиций Республики Калмыкия, привлечению новых потоков туристов в регион.

Экономическая сущность этнокультурного потенциала заключается в синтезе ресурсов этнической культуры, традиций и территориальной уникальности и основных целей и задач социального и экономического развития региона и повышения конкурентоспособности.

Для оценки этнокультурного ресурсного потенциала необходимо решение следующих задач:

- разработка методов и инструментов, позволяющих оценивать уровень этнокультурного потенциала;

- анализ использования этнокультурного потенциала региона;

- оценка вклада этнокультурного ресурсного потенциала в повышении конкурентоспособности региона;

- формирование основных перспектив использования этнокультурного потенциала страны и региона.

Изучение этнокультурного потенциала, представляет собой весьма непростую методологическую проблему, в частности, исследование затрудняют следующие проблемы:

- с одной стороны, культура человечества есть единый естественно-исторический процесс, поэтому в основе этнических культур лежат изначальные ментальные универсалии, с другой стороны, каждая этническая 
культура стремится отстоять собственную уникальность;

- на этническую культуру с неизбежностью влияют объективные общецивилизационные процессы, размывающие ее своеобразие, что ставит вопрос об аутентичности культур;

- в силу особенностей исторического развития и собственного состояния культуры оказываются под угрозой насильственного уничтожения (что и произошло со многими культурами в истории), ассимиляции, модификации; «встречным процессом» становится появление неотрадиционалистских тенденций в культуре;

- ни одна этническая культура не повторяет строгого набора признаков, характерных для другой культуры;

- культура коренных этносов не всегда является доминирующей, что требует дополнительных усилий по ее сохранению и развитию.

Заметна положительная динамика роста спроса на оказание туристических услуг. Если в 2012 г. объем туристско-экскурсионных услуг составлял 8 \% от общего объема услуг, то за 2015 год он составил уже $15 \%$ (см. рисунок).

Республика Калмыкия признана одним из самых благоприятных регионов для развития этнокультурного туризма. Богатство и колорит культуры, исторические памятники, народные традиции и этническая уникальность Республики Калмыкия являются основой для развития туристской индустрии, предлагающей широкий спектр услуг российским и зарубежным туристам.
Развитие туристской дестинации республики имеет определенные перспективы для стимулирования развития экономики региона. Министерством культуры РФ разработана программа развития культуры и туризма в России до 2020 года. Программа представляет собой ряд мероприятий, методов и инструментов государственной политики, обеспечивающих достижение приоритетных целей государства.

Привлечение инвестиций из федерального бюджета и внебюджетных источников будет осуществляться посредством реализации участия в федеральных целевых программах «Развитие внутреннего и въездного туризма в Российской Федерации (2011-2018 гг.)», а также «Развитие культуры и туризма Российской Федерации (2013-2020 гг.)», целью которых определено повышение конкурентоспособности отечественного туристского рынка, удовлетворяющего потребности российских и иностранных граждан в качественных туристских услугах, что соответствует цели Концепции.

Предложенные программой механизмы для успешной реализации федеральной целевой программы предполагают достаточно активное участие со стороны общественных институтов в разработке и формировании решений по проектированию перспективных туристических и рекреационных комплексов, которые должны отвечать всем требованиям и стандартам развития туристической отрасли. В свою очередь, создание отдельной отрасли в сфере туризма даст возможность развития малого и среднего предприниматель-

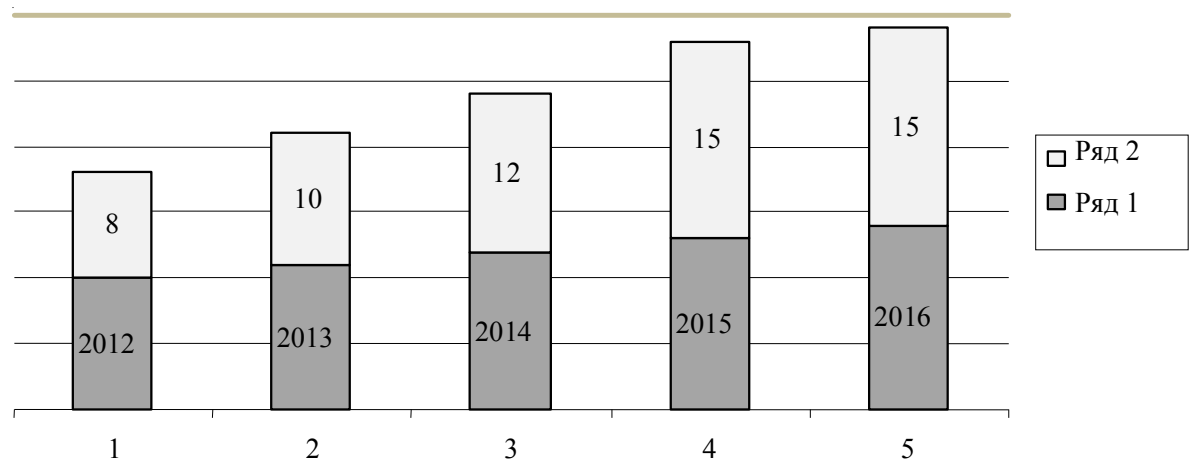

Рисунок. Динамика развития туристско-рекреационных услуг за 2012-2016 гг.

Примечание. Составлено автором по данным: [4]. 
ства, что предполагает создание новых рабочих мест и развитие территорий, что полностью соответствует приоритетам социального и экономического развития Российской Федерации [5].

Для эффективного развития туристической отрасли в регионе необходимо решить ряд задач:

- достижение материального благосостояния и, следовательно, повышения уровня жизни населения;

- развитие экономики через создание имиджа республики в интеграционных процесcax ЮФО и прикаспийского региона;

- обеспечение роста потока инвестиций.

Изучение и анализ туристического потенциала региона позволяет судить о том, что уровень привлекательности и возможностей республики за последние годы увеличиваются и туризм является одним из перспективных направлений экономического развития Республики Калмыкия.

Таким образом, вектор развития туристической отрасли в экономике призван способствовать повышению уровня жизни и культуры населения, продвижению статуса региона на федеральном уровне, повышению конкурентоспособности региональной экономики, а также обеспечить положительную динамику социально-экономического развития, которое выражено в развитии инфраструктуры региона, снижении уровня безработицы, росту уровня жизни населения и создании новых предпосылок для развития малого и среднего предпринимательства.

Так же в рамках Программы по развитию туризма была разработана подпрограмма «Туризм», которая предусматривает:

- включение объектов культуры в систему туристической деятельности;

- проведение работы, связанной с развитием туристско-рекреационного комплекса;

- развитие социального туризма к объектам культурного, исторического и природного наследия социально слабо защищенных категорий граждан;

- развитие культурно-образовательного туризма для стимулирования роста образованности населения, повышения уровня и укрепления позиции Российской Федерации в глазах иностранных туристов;
- меры по продвижению туристического продукта России на внутреннем рынке и за рубежом.

Подпрограммой «Туризм» предусмотрено содержание бюджетных ассигнований для финансирования проектов развития туристической отрасли. Общий объем бюджетных ассигнований федерального бюджета составляет 3652 814,5 тыс. руб., в том числе: на 2013 г. 357903 тыс. руб.; на 2014 г. - 728 550,6 тыс. руб.; на 2015 г. - 328 816,4 тыс. руб.; на 2016 г. 328 993,7 тыс. руб.; на 2017 г.-211 502,2 тыс. руб.; на 2018 г. - 277 291,1 тыс. руб.; на 2019 г. 697 181,4 тыс. руб.; на 2020 г. - 722 576,1 тыс. рублей.

В рамках реализации государственной программы по развитию туризма в Российской Федерации была разработана Концепция по развитию этнокультурного туризма в Республике Калмыкия на 2015-2018 годы. Согласно Концепции были разработаны основные приоритетные задачи для развития этнокультурного туризма на уровне региона [2]:

- совершенствование механизма в области управления развитием туристической сферы;

- создание условий для привлечения инвестиций;

- развитие систем маркетинга, который включает основных участников рынка и обеспечивает комплекс мер по производству, рекламе и продаже услуг;

- увеличение числа субъектов туристской деятельности в сельских и муниципальных образованиях региона;

- совершенствование нормативно-правовой базы в области туризма;

- стимулирование государственной поддержки проектов этнокультурного туризма.

В целом, осуществление положений подпрограммы «Туризм» и федеральной целевой программы «Развитие внутреннего и въездного туризма» на 2013-2018 гг. проходит в соответствии с намеченным графиком поставленных задач. Так, например, создаются проекты туристских маршрутов, проходит реставрация культурных и исторических достопримечательностей, облегчается визовый режим для иностранных туристов, уже прошла работа с налоговыми льготами для участников туристского рынка. 
Таким образом, в целях поддержки развития этнокультурного туризма и туристической индустрии в целом, необходимо разработать четко выработанный порядок действий, направленных на привлечение внебюджетных источников, которые могут быть достигнуты в результате формирования благоприятного инвестиционного климата, а также, за счет налоговых льгот и предоставления земельных участков для строительства гостиниц, мест общественного питания и других объектов, связанных с туристской инфраструктурой. Всего этого можно достичь путем участия в федеральных целевых программах, с целью привлечения инвестиций из федерального бюджета и внебюджетных источников, а также на участие в федеральных и международных грантах.

Богатейшие природно-рекреационные ресурсы, климатическое разнообразие, многонациональный колорит, а также культурное наследие России послужили базой для планирования развития внутреннего туризма. Благодаря чему, была разработана и посвящена федеральная целевая программа по развитию туристической индустрии в России. Основной государственной программой по развитию туризма на федеральном уровне является программа «Развитие культуры и туризма на 2013-2020 гг.».

В основе реализации государственной программы лежит реализация повышения потенциала культуры и туризма в России и регионах. Данная программа сформирована Министерством культуры РФ и призвана достичь основных направлений развития культуры и туризма в России до 2020 года. Программа включает ряд мероприятий, методов и инструментов государственной политики, которые обеспечат достижение приоритетных целей государства.

Как показывает мировая практика, этнокультурный туризм способен удовлетворить потребности самых взыскательных туристов. Ключевой составляющей в организации этнокультурного туризма является знакомство участников маршрута с культурой, традициями и историей различных этносов.

Европейский этнокультурный туризм сочетает в себе особенности исторического и гастрономического туризма, потому что исторически европейское общество делилось на сословия и классы. Вследствие чего, каждое из сословий имело свой быт и характерные черты. Так, например, в Праге проводятся фольклорные концерты в разбойничьем стиле или прогулки по ремесленной «Золотой улочке».

Зарубежная туристическая индустрия, имея отличный от российского исторический путь развития, а также в силу особенностей менталитета жителей разных стран, в свою очередь, ориентирована на:

- четкое выявление потребностей и желаний клиента еще на стадии установления контакта и стремление к их максимальному удовлетворению;

- установление долгосрочных отношений с клиентом, потому что именно долгосрочные отношения - главный показатель эффективности работы фирмы и качества обслуживания;

- информированность и создание информационной среды, способствующей значительному увеличению объема продаж и скорости обслуживания.

Любой тип традиции - это опыт, который накапливается и проявляется в виде системы стереотипов, реализуется в следующих формах: обычаи, обряды, ритуалы, церемонии, представления и праздники. Но самой яркой, сложной и характерной формой традиции является массовый праздник - это ритм жизни, его смысл не в развлекательности и отдыхе, а в удовлетворении потребности людей в реализации коллективной памяти, в участии в сотворчестве-диалоге между прошлым и будущим, иначе говоря, потребность быть в гуще жизни, ощутить ее пульс и живое дыхание.

Оценка эффективности использования этнокультурного ресурсного потенциала заключается в оценке этнокультурной политики. В результате роста этнокультурных потребностей неизбежно усложняется процесс государственного обеспечения и регулирования, который заключается, в основном, в разработке целевых программ. Ключевым принципом любой государственной программы является ее эффективность и результативность. Под эффективностью целевой программы понимается «цена» реализации проекта и количество затрат относительно результатов. Результативность целевой государственной программы - соответствие ожидаемых результатов поставленным целям и задачам. 
Развитие туристической отрасли позволяет не только прикоснуться к истокам истории целого народа и его национальной культуры, но и изучить новые, ранее не известные традиции и культуру, расширяя кругозор обычного городского обывателя. Более того, этнокультурный и событийный туризм - это форма проведения культурного досуга как для семейного отдыха, так и для молодого поколения, интересующегося историей и традициями своих предков, отличительной чертой которых является территориальная неограниченность, так как рассчитан заинтересовать как граждан России, так и иностранных туристов.

\section{СПИСОК ЛИТЕРАТУРЫ}

1. Авалдыкова, Е. С. Развитие туристических дестинаций, как инструмент повышения конкурентоспособности региональной экономики / Е. С. Авалдыкова, М. С. Бедняев, Н. А. Буркутбаева [и др.] // Экономика и предпринимательство. - № 4. - 2017. - С. 323-325.

2. Инвестиционная стратегия Республики Калмыкия на 2014-2020 гг. от 27 марта 2014 г. № 37. Электрон. текстовые дан. - Режим доступа: http:// docs.cntd.ru/document/430562190. - Загл. с экрана.

3. Информационный портал Республики Калмыкия. - Электрон. текстовые дан. - Режим доступа: http://tegrk.ru. - Загл. с экрана.

4. Официальный сайт Федеральной службы государственной статистики Республики Калмыкия. - Электрон. текстовые дан. - Режим доступа: http://statrk.gks.ru. - Загл. с экрана.
5. Республиканская целевая программа «Государственная поддержка туристской деятельности в Республике Калмыкия на 2013-2018 гг.» от 11 окт. 2012 г. № 371. - Электрон. текстовые дан. - Режим доступа: http://minsoc.socinfo.ru/img/upload/216/ documents/3gosp_soc.pdf. - Загл. с экрана.

\section{REFERENCES}

1. Avaldykova E.S., Bednyaev M.S., Burkutbaeva N.A., et al. Razvitie turisticheskikh destinatsiy, kak instrument povysheniya konkurentosposobnosti regionalnoy ekonomiki [The development of tourist destinations, as a tool to improve the competitiveness of the regional economy]. Ekonomika i predprinimatelstvo, 2017, no. 4, pp. 323-325.

2. Investitsionnaya strategiya Respubliki Kalmykiya na 2014-2020 gg. ot 27 marta 2014 g. № 37 [Investment Strategy of the Republic of Kalmykia for 2014-2020 of March 27, 2014 No. 37]. URL: http:// docs.cntd.ru/document/430562190.

3. Informatsionnyy portal Respubliki Kalmykiya [Information Portal of the Republic of Kalmykia]. URL: http://tegrk.ru/archives/30987.

4. Ofitsialnyy sayt Federalnoy sluzhby gosudarstvennoy statistiki Respubliki Kalmykiya [Official Website of the Federal State Statistics Service of the Republic of Kalmykia]. URL: http://statrk.gks.ru.

5. Respublikanskaya tselevaya programma "Gosudarstvennaya podderzhka turistskoy deyatelnosti v Respublike Kalmykiya na 2013-2018 gg.» ot 11 okt. 2012 g. № 371 [Republican Target Program 'State Support for Tourist Activity in the Republic of Kalmykia for 2013-2018' of October 11, 2012 No. 371]. URL: http://statrk.gks.ru.

\section{Information about the Authors}

Elena S. Avaldykova, Assistant, Department of Management, Postgraduate Student, Kalmyk State University named after B.B. Gorodovikov, Ippodromnaya St., 91/7, 358005 Elista, Republic of Kalmykia, Russian Federation, awaldykowa.lena@yandex.ru.

Tamara T. Tsatkhlanova, Doctor of Sciences (Economics), Professor of Department of Economics, Kalmyk State University named after B.B. Gorodovikov, Ippodromnaya St., 91/7, 358005 Elista, Republic of Kalmykia, Russian Federation, awaldykowa.lena@yandex.ru.

\section{Информация об авторах}

Елена Саранговна Авалдыкова, ассистент кафедры менеджмента, аспирант, Калмыцкий государственный университет им. Б.Б. Городовикова, ул. Ипподромная, 91/7, 358005 г. Элиста, Республика Калмыкия, Российская Федерация, awaldykowa.lena@yandex.ru.

Тамара Тавиновна Цатхланова, доктор экономических наук, профессор кафедры экономики, Калмыцкий государственный университет им. Б.Б. Городовикова, ул. Ипподромная, 91/7, 358005 г. Элиста, Республика Калмыкия, Российская Федерация, awaldykowa.lena@yandex.ru. 